\title{
Identifying diagenesis in Phanerozoic carbonates using triple oxygen isotopes
}

\author{
JORDAN WOSTBROCK ${ }^{1}$, ZACHARY SHARP ${ }^{2}$ AND UWE \\ BRAND $^{3}$
}

${ }^{1}$ Yale University

${ }^{2}$ University of New Mexico

${ }^{3}$ Brock University

Presenting Author: jordan.wostbrock@yale.edu

Paired $\delta^{17} \mathrm{O}-\delta^{18} \mathrm{O}$ measurements of marine carbonates allow the water's oxygen isotope value to be calculated because there is only one unique solution for a given temperature for equilibrium calcite-water fractionation. This is important when measuring ancient samples where the water is no longer present. Using the three isotopes of oxygen allows for a definitive identification of diagenesis - samples that fall off the unique triple oxygen isotope equilibrium curve must have undergone some degree of diagenesis. A fluid-rock mixing model can be used to 'see through' alteration in samples such that the initial temperature of formation and the oxygen isotope value of the water in which the carbonate formed can be calculated.

In this study, we compile published Phanerozoic marine carbonate data and add four new brachiopod samples to determine the temperatures and oxygen isotope values of the Phanerozoic ocean in which these samples formed. All brachiopod samples were previously published as having minimal diagenesis and range in age from Ordovician to Eocene. Only three samples (Eocene, Cretaceous, and Silurian brachiopods) have triple oxygen isotope values that suggest the carbonate formed in an ocean with a $\delta^{18} \mathrm{O}$ value between -1 and 0 $\%$ and at a temperature between 25 and $32{ }^{\circ} \mathrm{C}$. This implies that at least since the Silurian, the ocean where these carbonates formed had oxygen isotope values similar to modern oceans $+/-1$ $\%$ for the expected change in ice-free ocean conditions. The triple oxygen isotope compositions of the remaining samples are not in equilibrium with modern or ice-free ocean water. Using a simple fluid-rock mixing model, we can see through the alteration and calculate the initial temperature of formation in an ocean with a $\delta^{18} \mathrm{O}$ value of $-1 \%$ (for an ice-free ocean climate). The calculated 'pristine' values of the altered samples all suggest a temperature of formation below $30^{\circ} \mathrm{C}$ in marine waters. Based on this limited data set, it appears that the secular trend observed in the deeper-time Phanerozoic geologic record represents diagenesis rather than changes in temperature or ocean oxygen isotope composition. 